\title{
Political Autonomy and Independence: Theory and Experimental Evidence
}

\author{
by KLAUS ABBINK* and JORDI BRANDTS** \\ * CREED, University of Amsterdam \\ ** Institut d'Anàlisi Econòmica (CSIC), Barcelona
}

March 2007

\begin{abstract}
We study the process by which subordinated regions of a country can obtain a more favourable political status. In our theoretical model a dominant and a dominated region first interact through a voting process that can lead to different degrees of autonomy. If this process fails then both regions engage in a costly political conflict which can only lead to the maintenance of the initial subordination of the region in question or to its complete independence. In the subgame-perfect equilibrium the voting process always leads to an intermediate arrangement acceptable for both parts. Hence, the costly political struggle never occurs. In contrast, in our experiments we observe a large amount of fighting involving high material losses, even in a case in which the possibilities for an arrangement without conflict are very salient. In our experimental environment intermediate solutions are feasible and stable, but purely emotional elements prevent them from being reached.
\end{abstract}

\section{Keywords}

Secession, collective action, independence movements, laboratory experiments, rent-seeking

\section{JEL Classification Codes}

C92, C93, D72, D74

\section{Acknowledgements}

Financial support from the Spanish Ministerio de Ciencia y Tecnologia (BEC 2003-00412), the Ministerio de Educación y Cultura (SEJ2005-01690), the Barcelona Economics program of CREA, the British Academy and the University of Nottingham is gratefully acknowledged. This research has been carried out while Abbink was a visitor at the Institut d'Anàlisi Econòmica (CSIC), Barcelona. He gratefully acknowledges their hospitality and support. The authors thank David Rodríguez and Javier Valbuena for help in running the experiments.

Author addresses

\begin{tabular}{ll}
\hline \multicolumn{1}{c}{ Klaus Abbink } & \multicolumn{1}{c}{ Jordi Brandts } \\
\hline CREED & Institut d'Anàlisi Econòmica (CSIC) \\
Faculty of Economics and Econometrics & Campus UAB \\
University of Amsterdam & 08193 Bellaterra \\
Roeterstraat 11 & Spain \\
1018 WB Amsterdam & \\
The Netherlands & \\
Phone +31-20-525.4229 & Phone +34-93-5806612 \\
Fax +31-20-525.5283 & Fax +34-93-5801452 \\
k.abbink@uva.nl & jordi.brandts@,uab.es \\
\hline
\end{tabular}




\section{Introduction}

Many countries consist of several parts or regions with populations that have different interests or identities. Often one of the parts of the country is politically dominant due to its size, historical circumstances or other reasons. In many of such cases there are conflicts peaceful or violent - over parts of countries attempting to obtain more political autonomy or to secede and obtain independence. Different degrees of political autonomy including independence imply differences in the allocation of government spending, in tax arrangements, in the degree of self-government between the communities involved, as well as in the satisfaction that derives from more or less possibilities of cultural expression and recognition. In figure 1 we show just some of the places in the world with such ethno-political conflicts.

The process by which such regions obtain a different political status can be very costly and often violent. For instance, the civil war fought over a Kurdish state independent from Turkey $^{1}$ has claimed about 30,000 lives, without any sign of success for the seceding party. Separatists in East Timor have been more successful, since the country gained fully recognised sovereignty in 2002. Independence came at a price, though, with a death toll of at least 100,000 in a 25-year civil war with Indonesia. The struggle for Abkhazia's secession from Georgia, which resulted in the region's de facto independence ${ }^{2}$, involved an act of ethnic cleansing displacing 250,000 ethnic Georgians. Even in less violent cases the costs of such conflicts can be substantial. Abadie and Gardeazabal (2003) estimate that terrorism and political instability arising from the Basque conflict have led to a decline of per capita GDP of about 10 percentage points. In other cases the record is less bleak. In the last twenty years Catalonia has reclaimed considerable legislative powers from Spain in a purely political nonviolent process. Similarly, the sovereignist movement of Québec peacefully achieved substantial concessions from Canada and in 1995 even forced a referendum on full sovereignty. The motion failed only by the narrowest of margins ( $49.4 \%$ versus $50.6 \%)$.

The question arises as to why the different regions are often not able to agree on an intermediate solution to the conflict, involving some degree of power sharing, while others are able to compromise without bloodshed. In many cases the struggle revolves around the extreme solutions; it is about whether the dominant region maintains complete control or whether independence - or a similar status - of the dominated region is attained. One possible explanation for this is that intermediate solutions are somehow not stable, because, due to the particular set of feasible distributions of resources, they are very unsatisfactory for the regions involved. The interdependence of preferences may play a role here. For example, if the

\footnotetext{
${ }^{1}$ Significant Kurdish populations are also resident in Syria, Iran and Iraq. In the latter country they run a de facto independent region without much interference from Baghdad.

${ }^{2}$ The Republic of Abkhazia has not been recognised by any country, but the central government in Georgia has no control over the region. Power is entirely held by the regional government, allegedly supported by Russia.
} 
recognition of some of the symbolic identifiers of one of the regions is in a way unbearable for the inhabitants of the other region then an intermediate solution may be hard to implement.

Another explanation is that intermediate solutions are in a material sense stable, but that purely emotional forces, which arise in the process of attempting to find an intermediate solution, prevent them from being reached. What emotional forces could come into play here? One possibility is that when different strongly cohesive communities are involved then conflict as such is positively valued. Another possibility is that the fact that the starting point is a status quo involving the preponderance of one of the regions makes it very hard for the citizens of the dominated region to accept the process.

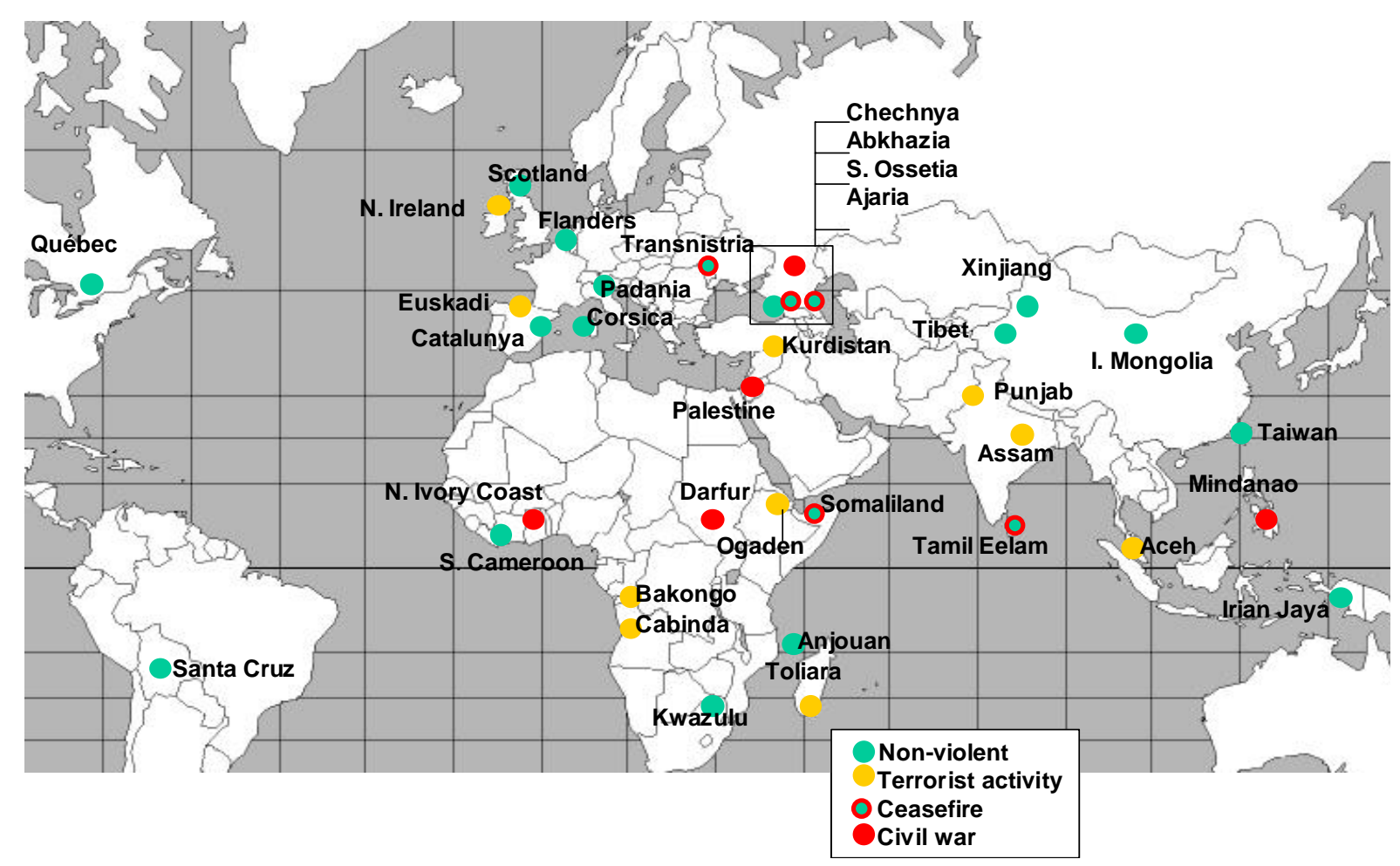

Figure 1. Ethno-political conflict in the world

In this paper we combine a theoretical model and the analysis of experimental data based on an implementation of the model to shed light on some of the issues just discussed. First, we present a simple theoretical model in which to study the purely material payoff-based determinants of whether intermediate solutions can be reached and, hence, costly conflict can be avoided. The experiment we designed is directed at identifying some of the emotional forces mentioned in the previous paragraph. It has been shown that group sentiment and dissatisfaction with the process by which certain payoffs are reached can influence behaviour in experiments. With the experiments we present here we want to find out whether such influences are also significant in the kind of political environments that we are interested in. 
There is a long tradition of modelling political conflict in game-theoretic terms. One of the early contributions is Schelling (1960) "The Strategy of Conflict". Indeed, since its beginnings game theory has been used to study the strategic aspects of military and political conflicts. Currently issues of power-sharing and secession are being studied both in economics and political science. Alesina and Spolaore (1997) study the equilibrium determination of the number of independent countries under different political and economic conditions, Le Breton and Weber (2003) construct a model of a country with heterogeneous population and examine compensation schemes that may prevent a threat of secession by dissatisfied regions, Jehiel and Thisse (2005) look at issues of collective decision-making within a confederation of independent countries and Esteban and Ray (2005) study the interaction between population size, income in equality and ethnic activism. Hechter (2000) suggests how nationalistic violence can be contained, Hale (2000 and 2004) tests several theories of secession in the Soviet setting and takes a broader look at the determinants of federal success, Wood (2003) analyses the determinants of civil war settlements and Lustick, Miodownik and Eidelson (2004) study whether power sharing arrangements prevent or encourage secession in multicultural states. Ruta (2005) and Kyriacou (2005) contain recent surveys of work on these issues.

The issue of secession and the fight for independence has, to our knowledge, not been previously studied experimentally. Even the more general experimental literature on political conflict is surprisingly sparse. A few experiments on political systems focus on the emergence of regimes in a model in which citizens can devote their efforts to production or appropriation (Durham, Hirshleifer, and Smith (1998), Carter and Anderton (2001), Duffy and Kim (2004)). Others (Abbink and Pezzini (2005), Cason and Mui (2006)) study revolting behaviour in a dictatorship. With the conflict model we use our study is also related to the literature on rentseeking games (Millner and Pratt (1989), Potters, de Vries, and van Winden (1998), Weimann, Yang, and Vogt (2000), Anderson and Stafford (2003)).

We show under which conditions the subgame-perfect equilibrium of our game leads to an intermediate arrangement acceptable for both parts without any costly political conflict. In contrast, in the experiments based on the model we observe a large amount of fighting involving high material losses, even in a case in which the possibilities for an arrangement without conflict are very salient. In our experimental environment intermediate solutions are feasible and stable, but purely emotional elements prevent them from being reached.

\section{The model}

Before we introduce the details of the model we want to briefly discuss some of the essential features of the kind of context that we want to represent. We start by saying that we do not model an authoritarian situation in which a single individual or a small group dictates the political outcome. Rather, we focus on conflicts between different communities as such, 
which initially live together under certain rules that favour one of the communities. In such cases the process by which a change in the political arrangement is sought often has a democratic character, but suffers from the difficulty that the citizens of the dominant region inevitably are the majority in the political entity. Hence they can prevent the dominated region from obtaining a more satisfactory status. Given these circumstances, the citizens of dominated regions may consider the outcome of this particular democratic process unacceptable and may organise to reject it. A problem of legitimacy of the process may lead to conflict.

Another central aspect of our model is that only a given set of payoff distributions are feasible. This is a standard for an economic approach to the problem. However, it is important to point out that we see this mainly as a short run restriction. In the long run the feasible arrangements can be changed. Economic growth naturally pushes out the material frontier, new infrastructures may favour both regions and constitutional innovations also enlarge the space of what can be accomplished. Finally in the realm of symbolic representation and community time may also change things in favour of intermediate arrangements. Here we focus on the situation at a particular point in time.

The third building block of our model that we want to highlight at this point is our representation of conflict. We represent conflict as an intense sort of rivalry, in the sense that only one of the sides involved can obtain its preferred status. Conflict involves potentially large losses. In the way we model things, the losses from conflict will be inefficiencies that need not occur. The study of how these inefficiencies arise and how they can be avoided is the main motivation for our work.

We now present the model in a general version, in section 2.2 we will introduce the specific parameter configurations that we use in our experiments. We start with agents and preferences. A state or country is divided into two exogenously given regions, A and B. In region $A$ there are $n_{A}$ type $A$ citizens, region $B$ is inhabited by $n_{B}$ type $B$ citizens. We assume $\mathrm{n}_{\mathrm{A}}>\mathrm{n}_{\mathrm{B}}$, type A citizens are the majority in the state.

In accordance with many real-life cases, the smaller region is the one striving for a more favourable institutional arrangement. Type A citizens prefer the status quo which can be interpreted as a centralised regime, while type B citizens prefer other possible institutional arrangements and their ideal state of the world is at the other extreme of the policy space, which we envision as being complete autonomy or independence. For simplicity, we assume that all citizens within one region have identical preferences with respect to region B's autonomy. ${ }^{3}$

In between complete centralisation and complete independence there are various levels of autonomy that region B can be granted. In this section we assume, to keep things neat, a

\footnotetext{
${ }^{3}$ It is possible to allow for some heterogeneity in the model without changing the main results. It is sufficient to require a majority of citizens in each region to have a certain type of preferences.
} 
continuous measure of possible regimes, ordered from 0 (complete centralisation) to 1 (independence). ${ }^{4}$ Different values on this line represent different combinations of selfdetermination rights. Along this line, type A individuals prefer a smaller value to a larger one, while type $B$ individuals always prefer the larger one. Without loss of generality we normalise type A citizens' utility of full independence to zero, and denote their utility from full centralisation as $\Delta_{\mathrm{A}}$.

The ordering follows the citizens' preferences, but there is no meaningful scale that can be given to the zero to one range. We therefore normalise the variable in a way that the type A individuals' utility is a linear function of the autonomy level $\mathrm{x}$, i.e. $\mathrm{u}_{\mathrm{A}}(\mathrm{x})=-\mathrm{x} \Delta_{\mathrm{A}}$. The utility of a type $B$ citizen, which we denote by $f(x)$, is then an increasing function of the autonomy level, and implicitly a decreasing function of type A's utility. ${ }^{5}$ Note that there is no a priori natural assumption to be made about the curvature of $\mathrm{f}$. This is because $\mathrm{f}$ reflects the relative strength of preferences between the two types of individuals. ${ }^{6}$ Figure 2 depicts an example constellation.

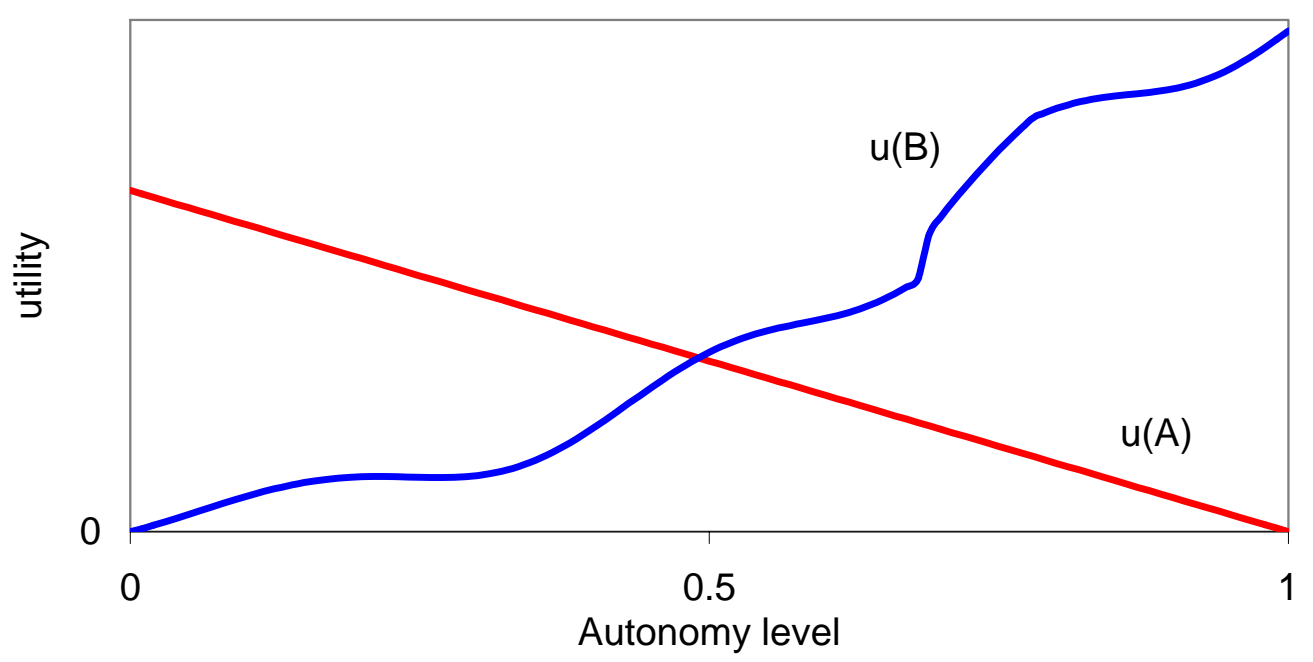

Figure 2. Utility functions for citizens of both types

With this framework of preferences, we can now construct the strategic model. Our game consists of up to four stages. The four stages represent what we think are the crucial steps in the process by which a new institutional arrangement between the two regions is reached. Consider that at the outset of the game the state is organised in full centralisation. This assumption is not crucial for the analysis of the game that we present below, but it

\footnotetext{
${ }^{4}$ Continuity is not crucial for the analysis. It will turn out that very similar results can be obtained if the function has kinks, jumps, or even a discrete domain.

${ }^{5}$ Monotonicity is not technically required, but is a sensible assumption. If there is a policy measure that makes both types of citizens better off, it should simply be implemented and is not part of the interregional conflict.

${ }^{6}$ Implicitly we assume that interpersonal comparison of preferences is feasible and meaningful, which would be the case if utilities represent money equivalents.
} 
corresponds to the frame that we present to subjects in the experiment. We consider that the initially dominant region A has the political initiative at the beginning of the process. Region $B$ then reacts to A's initiative.

To represent this, in the first stage it is one of the type A player who proposes a level of autonomy, $\mathrm{x}$, between 0 and 1 inclusively, over which the citizenship as a whole - all As and all Bs - will decide by a majority vote. Lacking a natural "leader" in the experimental context, we opted for having the proposer randomly selected among all A type players. ${ }^{7}$ This should be seen as a very simplified representation of a process in which the A type citizens have all the initiative. All type A players are identical and they are in the majority with respect to the B types. Thus, if there is a proposal that is optimal for the type A players, it should be expected to always be made and always win the ballot. The voting behaviour of the type B citizens will not matter in this case.

The second stage consists in the majority rule voting decision advanced above: all citizens, including both type $\mathrm{A}$ and type $\mathrm{B}$, vote on this proposal versus the status quo of full centralisation. The winning alternative becomes the starting point for the third stage of the game.

In the third stage type B citizens vote on whether or not they open a conflict for full independence. If a majority votes against the conflict then the interim status quo (the winner of the previous voting stage) is implemented. If a majority votes in favour of opening the conflict for independence, then the conflict - the fourth stage of the process - is fought out. The voting process in the third stage is meant to be a very stylised rendering of the political interaction that takes place between the citizens of the subordinate region.

The winners of the conflict (either citizens A or B) get their most preferred state implemented, i.e. full centralisation if the citizens $\mathrm{A}$ win, and complete independence if the citizens $\mathrm{B}$ are victorious. This reflects that after a conflict the winning side can impose its rule on the losers.

Who wins the conflict is determined using a binary lottery. Before the actual fight takes place, each citizen can contribute to its group's "war chest". 8 Thus a type B citizen contributes to the independence campaign of region B, and a type A citizen contributes to its region's movement to maintain complete centralisation. After the contributions have been made, a binary lottery is played out. If the outcome is in region B's favour, then region B becomes an independent state. Each type A citizen receives a payoff of zero, each type B citizen gets $f(1)$. If region A wins the lottery, then the original status quo of full centralisation is implemented.

The probability with which the two groups win is determined by

\footnotetext{
${ }^{7}$ However, it will be seen that the structure of the proposal process does not affect the theoretical results.

${ }^{8}$ This term is not to be taken literally. The fourth stage contest might represent a violent conflict, but it does not need to be that way. The contributions could as well stand for efforts taken in political campaigns, like demonstrations, strikes, or propaganda. The recent history of non-violent revolutions (e.g. in Yugoslavia, Georgia, Bolivia, or Ukraine or Kyrgyzstan) shows that these methods can effectively overturn political systems.
} 


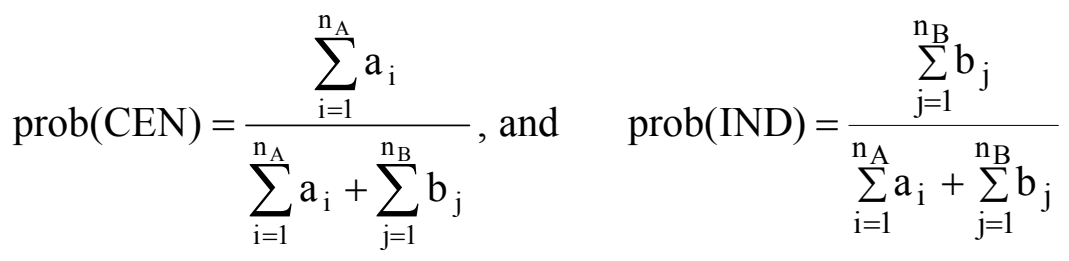

where CEN denotes full centralisation, IND stands for independence. The variables $a_{i}$ and $b_{j}$ denote the individual contributions of a type A or type B citizen, respectively.

The last stage subgame is a variant of familiar rent-seeking games, in which players compete for a prize by investing in campaigning. This is, in our view, a very natural way of representing the kind of wasteful rivalry that we want to portray here and is commonly used in conflict models (e.g. Esteban and Ray (2005)). One difference of our game to the standard rent-seeking model is that the players are groups whose voluntary contributions form the investment in rent-seeking. Further, the prize may differ for the two groups, which is also non-standard in the rent-seeking literature. ${ }^{9}$

\subsection{Game theoretic analysis}

We now turn our attention to the equilibrium analysis of our model. For the theoretical analysis we conventionally assume that each player maximises his own expected utility. We study the symmetric subgame perfect equilibria of the game.

At the final stage of the game, each citizen contributes to his region's war chest. For convenience we define the variable $\Delta_{\mathrm{B}}$ which denotes the difference in a citizen B's payoff between the best (full independence) and the worst (full centralisation) outcome. Recall that for the type A players this difference is $\Delta_{\mathrm{A}}$ due to the normalisation of their utility from full independence to zero, while for the type B players this difference is $\Delta_{B}=f(1)-f(0)$. We first look at a type B player's maximisation problem. The citizen maximises the expected payoff, which is determined by the stakes in the lottery and the probability of winning. Thus the player maximises

$$
\Pi_{\mathrm{A}}=\Delta_{\mathrm{A}} \frac{\mathrm{a}_{\mathrm{i}}+\mathrm{A}_{-\mathrm{i}}}{\mathrm{a}_{\mathrm{i}}+\mathrm{A}_{-\mathrm{i}}+\mathrm{B}}-\mathrm{a}_{\mathrm{i}}
$$

where $a_{i}$ denotes player i's contribution, $A_{i}$ the aggregate contribution of all other type $A$ players, and B the aggregate contribution of all type B players. Note that player A's payoff in the case of not winning the lottery is normalised to 0 .

After some rearrangements, the first order condition of the above maximisation problem

$$
\mathrm{a}_{\mathrm{i}}=\sqrt{\mathrm{B} \Delta_{\mathrm{A}}}-\mathrm{A}_{-\mathrm{i}}-\mathrm{B}
$$

\footnotetext{
${ }^{9}$ For experiments on rent-seeking where players are individuals see Millner and Prat (1989), Davis and Reilly (1998), Potters, de Vries and van Winden (1998) and Anderson and Stafford (2003).
} 
Symmetry of all players of the same type then requires that

$$
\mathrm{A}=\mathrm{n}_{\mathrm{A}} \mathrm{a}_{\mathrm{i}}=\sqrt{\mathrm{B} \Delta_{\mathrm{A}}}-\mathrm{B}
$$

A type B citizen's maximisation problem is analogously

$$
\Pi_{\mathrm{B}}=\frac{\mathrm{b}_{\mathrm{i}}+\mathrm{B}_{-\mathrm{i}}}{\mathrm{a}_{\mathrm{i}}+\mathrm{A}+\mathrm{B}_{-\mathrm{i}}} \pi_{\mathrm{B}}^{\mathrm{IND}}+\left(1-\frac{\mathrm{b}_{\mathrm{i}}+\mathrm{B}_{-\mathrm{i}}}{\mathrm{a}_{\mathrm{i}}+\mathrm{A}+\mathrm{B}_{-\mathrm{i}}}\right) \pi_{\mathrm{B}}^{\mathrm{CEN}}-\mathrm{b}_{\mathrm{i}} \rightarrow \max !
$$

With $\pi_{\mathrm{B}}^{\mathrm{IND}}-\pi_{\mathrm{B}}^{\mathrm{CEN}}=\Delta_{\mathrm{B}}$ and $\mathrm{B}_{-1}=\left(\mathrm{n}_{\mathrm{B}}-1\right) \mathrm{b}_{\mathrm{i}}-$ for symmetry - we obtain that

$$
\mathrm{B}=\mathrm{n}_{\mathrm{A}} \mathrm{b}_{\mathrm{i}}=\sqrt{\mathrm{A} \Delta_{\mathrm{A}}}-\mathrm{A}
$$

Substituting this into (1) yields after some rearrangements the type A player's contribution function

$$
\mathrm{a}_{\mathrm{i}}=\frac{1}{\mathrm{n}_{\mathrm{A}}} \Delta_{\mathrm{B}}\left(\frac{\Delta_{\mathrm{A}}}{\Delta_{\mathrm{A}}+\Delta_{\mathrm{B}}}\right)^{2}
$$

The contribution function for a type B player is completely analogous

$$
\mathrm{b}_{\mathrm{i}}=\frac{1}{\mathrm{n}_{\mathrm{B}}}\left(\frac{\Delta_{\mathrm{B}}}{\Delta_{\mathrm{A}}+\Delta_{\mathrm{B}}}\right)^{2}
$$

Perhaps not surprisingly, these reaction functions have a similar structure to those for standard rent-seeking games. If $\mathrm{n}_{\mathrm{A}}=\mathrm{n}_{\mathrm{B}}=1$ and $\Delta_{\mathrm{A}}=\Delta_{\mathrm{B}}$ then they are identical to each other. Note that rent dissipation decreases considerably as the groups become larger. Since $\Delta_{\mathrm{j}}$ is the prize that each individual of group $\mathrm{j}$ receives when winning the lottery, the total amount won by the winning team is $n_{j} \Delta_{j}$. The sum of all group members' contributions, however, just adds up to a contribution equivalent to the individual player case.

With the equilibrium contributions we can now calculate the expected payoff of conflict for a citizen of each region. The probability of region A winning the contest is obtained by substituting the equilibrium contributions into the probability function, thus

$$
\operatorname{prob}(\mathrm{CEN})=\frac{\left(\frac{\Delta_{\mathrm{B}}}{\Delta_{\mathrm{A}}+\Delta_{\mathrm{B}}}\right)^{2}}{\Delta_{\mathrm{B}}\left(\frac{1}{\Delta_{\mathrm{A}}+\Delta_{\mathrm{B}}}\right)^{2}+\left(\frac{\Delta_{\mathrm{B}}}{\Delta_{\mathrm{A}}+\Delta_{\mathrm{B}}}\right)^{2}}=\frac{\Delta_{\mathrm{A}}}{\Delta_{\mathrm{A}}+\Delta_{\mathrm{B}}} .
$$

Since a citizen's contribution is lost in any case, the A's expected payoff is

$$
\mathrm{E}\left(\Pi_{\mathrm{A}}\right)=\frac{\Delta_{\mathrm{A}}^{2}}{\Delta_{\mathrm{A}}+\Delta_{\mathrm{B}}}-\frac{1}{\mathrm{n}_{\mathrm{A}}} \Delta_{\mathrm{B}}\left(\frac{\Delta_{\mathrm{A}}}{\Delta_{\mathrm{A}}+\Delta_{\mathrm{B}}}\right)^{2}
$$


The expected payoff for a citizen B is calculated analogously. In any case a B citizen will get $\mathrm{f}(0)$, the payoff for the worst case of full centralisation. The additional expected payoff from conflict is then the winning probability times the prize, thus

$$
\mathrm{E}\left(\Pi_{\mathrm{B}}\right)=\mathrm{f}(0)+\frac{\Delta_{\mathrm{B}}^{2}}{\Delta_{\mathrm{A}}+\Delta_{\mathrm{B}}}-\frac{1}{\mathrm{n}_{\mathrm{B}}}\left(\frac{\Delta_{\mathrm{A}}}{\Delta_{\mathrm{A}}+\Delta_{\mathrm{B}}}\right)^{2}
$$

From here the analysis of the voting stages is straightforward. If there is an autonomy level which generates a higher utility than the expected payoff of conflict for both A and B citizens, then there will be no conflict. It is always better for a citizen A to propose such a level than one that leads to conflict. All players A vote for it rather than remaining at full centralisation in order to avoid conflict. ${ }^{10}$ Since the As form the majority, they will win the vote regardless of the voting behaviour of the citizens B. The citizens B will vote against opening conflict, since their utility at that autonomy level is higher than their conflict payoff as well. If there is more than one autonomy level that has these properties, then the proposing citizen A will pick the one with lowest autonomy, since an A's utility decreases with the level of autonomy.

One of the questions that brought us here is under what conditions an appeasement level of autonomy exists. It is not difficult to see that this depends on the shape of the citizens B's utility function.

Proposition. If the citizens B's utility function $\mathrm{f}(\mathrm{x})$ is concave, then there will be no conflict in a subgame perfect equilibrium of the game. ${ }^{11}$

Proof. It is sufficient to show that one autonomy level x exists which generates higher payoffs for both types of citizens than their respective expected payoff of conflict. Suppose $\mathrm{x}=\frac{\Delta_{\mathrm{B}}}{\Delta_{\mathrm{A}}+\Delta_{\mathrm{B}}}$. A citizen A's payoff at that autonomy level is $1-\mathrm{x}=\frac{\Delta_{\mathrm{A}}}{\Delta_{\mathrm{A}}+\Delta_{\mathrm{B}}}$. This is higher than the conflict payoff of $\frac{\Delta_{\mathrm{A}}}{\Delta_{\mathrm{A}}+\Delta_{\mathrm{B}}}-\frac{1}{\mathrm{n}_{\mathrm{A}}} \Delta_{\mathrm{B}}\left(\frac{\Delta_{\mathrm{A}}}{\Delta_{\mathrm{A}}+\Delta_{\mathrm{B}}}\right)^{2}$, since the citizen A does not pay contributions to the war chest. Concavity of citizen B's utility function implies that

$$
\begin{aligned}
\mathrm{f}\left(\frac{\Delta_{\mathrm{B}}}{\Delta_{\mathrm{A}}+\Delta_{\mathrm{B}}}\right) & \geq \mathrm{f}(0)+\left(\frac{\Delta_{\mathrm{B}}}{\Delta_{\mathrm{A}}+\Delta_{\mathrm{B}}}\right) \Delta_{\mathrm{B}}= \\
& =\mathrm{f}(0)+\frac{\Delta_{\mathrm{B}}^{2}}{\Delta_{\mathrm{A}}+\Delta_{\mathrm{B}}}>\mathrm{f}(0)+\frac{\Delta_{\mathrm{B}}^{2}}{\Delta_{\mathrm{A}}+\Delta_{\mathrm{B}}}-\frac{1}{\mathrm{n}_{\mathrm{B}}}\left(\frac{\Delta_{\mathrm{A}}}{\Delta_{\mathrm{A}}+\Delta_{\mathrm{B}}}\right)=\mathrm{E}\left(\Pi_{\mathrm{B}}\right) .
\end{aligned}
$$

Hence $f(x)>E\left(\Pi_{B}\right)$.

\footnotetext{
${ }^{10}$ In our equilibrium description we assume sincere voting. Strictly speaking, sincere voting is the unique best response only if a voter is pivotal. As a result there are multiple equilibria in which an individual voter's choice does not matter and thus any vote is a best response. However, since these equilibria involve playing weakly dominated strategies we select against them.
} 
Concavity is thus a sufficient, though not necessary, condition for the existence of a peace equilibrium. An example of such a constellation is depicted in figure 3, where we use $\mathrm{E}_{\mathrm{i}}$ (war) to refer to expected payoff from conflict. The intersection of the citizens B's utility function and the expected conflict payoff marks the left boundary of autonomy levels in which peace is at least as good as conflict. Autonomy levels to the left of that point would please the citizens A, but citizens B would prefer conflict. Levels to the right of the intersection of the citizens A's utility function and their conflict payoff would not be suggested by any player A, since they would leave the As worse off. All levels in between these boundaries improve the payoff for both types of citizens over their conflict level. Since the citizens A wish to maximise their payoff, they would propose the smallest autonomy level available that improves both types' payoffs, marked by the vertical line, labelled SPE for subgame-perfect equilibrium.

If the Bs' utility function is too convex, then an appeasement level of autonomy (and thus a peace equilibrium) does not exist. Strong convexity of B's utility function implies that to obtain sizeable increases in B's utility one has to lower A's considerably. In this case conflict is inevitable and one region will get its most preferred outcome. A constellation like this is illustrated in figure 4.

It is worth stressing that the existence of a peaceful interior equilibrium depends on the shape of the utility functions relative to one another. It does not depend on the intensity of the emotions attached to national sovereignty. It is well possible that self-determination issues stir strong emotions among the citizens of a state (or have substantial economic consequences), but nevertheless a peaceful agreement granting limited autonomy can be reached. On the other hand, even if national identity issues are relatively low-key, conflict may arise if the relevant utility function is convex.

\subsection{Experimental design and research questions}

The analysis of the previous section is based on the assumption that people are only motivated by their own material payoffs. However, we know from many other experiments on interactive situations that relative material payoffs, efficiency considerations, emotional forces, issues of process satisfaction etc. may also come into play and have substantial influence on behaviour. This is what we want to study with our experiment.

Starting with the first stage of the game, it is possible that the selected A citizens do not propose the payoff corresponding to the subgame-equilibrium presented in section 2.1 . Among the reasons for this there could be a concern for others' payoffs as well as a tendency to taking advantage of the position of initiative that the timing of the game gives to that player.

\footnotetext{
${ }^{11}$ One can think of this result as proposing when appeasement is possible. For some reflections on appeasement see Hirshleifer (2001).
} 


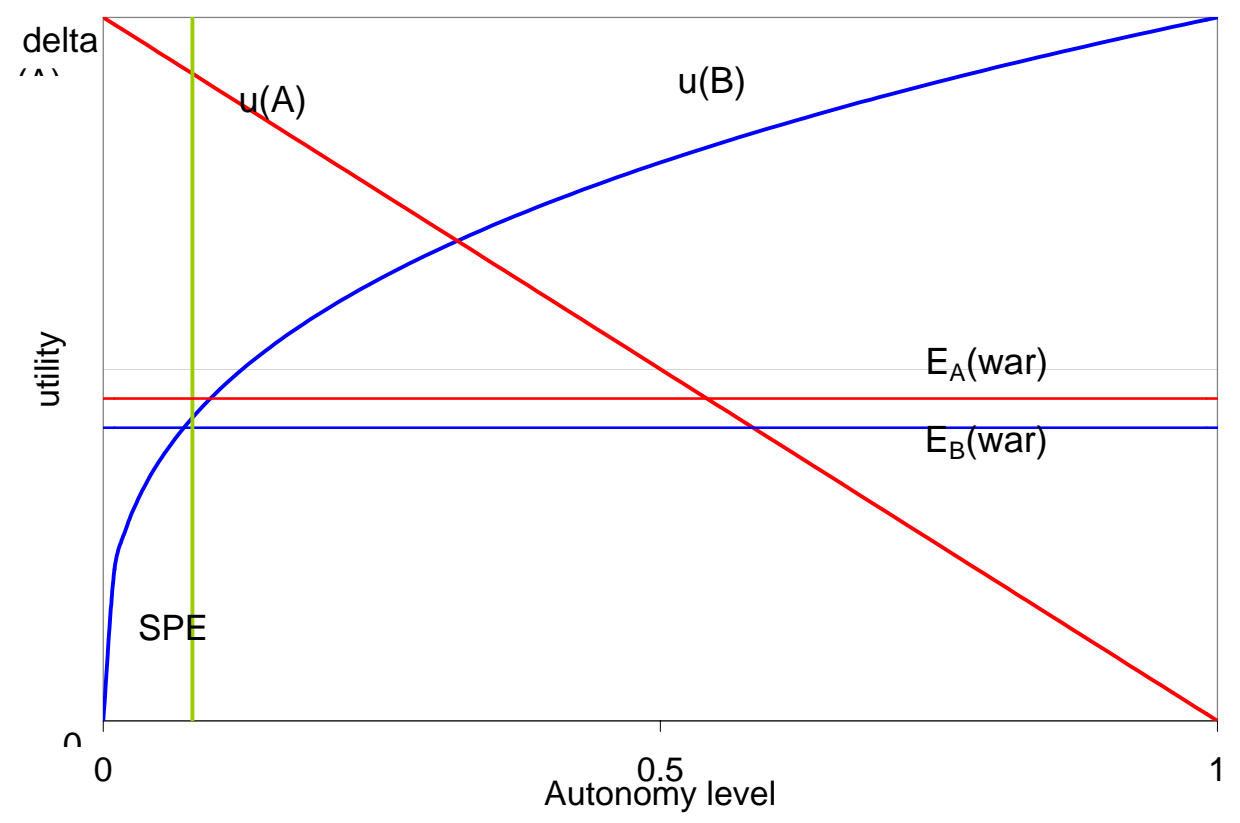

Figure 3. Concavity and peaceful subgame-perfect equilibrium

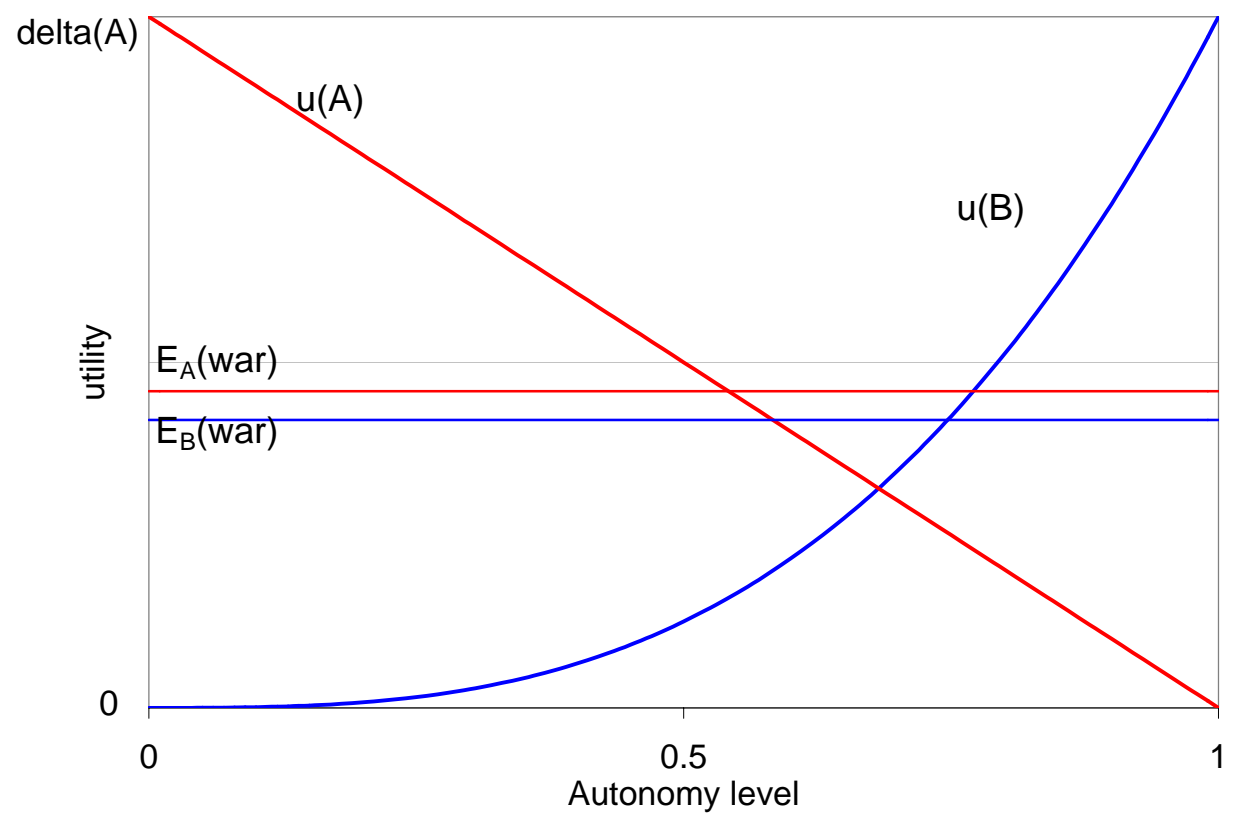

Figure 4. Convexity and the absence of a peaceful subgame-perfect equilibrium

At the voting stage deviations from the above analysis could take the form of a tough majority of As rejecting an equilibrium (or even a more favourable) offer made to the Bs. A perhaps more likely possibility is that tough Bs reject an equilibrium proposal to express their dislike of the situation, but possibly also in the hope of being (together with some tough As who reject the proposal for other reasons) in an overall majority who rejects the proposal. The motivation for Bs voting in this way could be the idea that the "the worse the better". Once the proposal has been rejected the game is back to the original status quo which is more likely to lead to a conflict when the Bs decide on it. 
In the third stage in which the Bs decide on the acceptance of the proposal that has come out of the referendum rejections of the equilibrium (or even better) proposals can again arise, as a result of the emotional forces mentioned above. The Bs may just be unsatisfied with the process as a whole and may want to express this.

Behaviour in the final fourth stage is also not easy to gauge beforehand. In the game as a whole the conflict stage should never be reached, However, we do have a prediction for the As' and Bs' contributions to the war chest, for the case that the conflict stage is effectively reached. The question that arises is how good that prediction will be. Once a reasonable proposal has been rejected by the Bs, this may open the door to very emotional behaviour and hence to above equilibrium contributions to the respective war chests.

The four possible deviations just discussed are the focus of our study. To get a more complete view of behaviour we also study some of the comparative statics of the model. In particular, we study three different degrees of concavity of the payoff functions and test whether "peace" equilibria are more likely to be achieved the more concave the preferences of the seceding region's citizens with respect to their autonomy level.

In all three treatments of the experiment there were six citizens of type $A$ and three citizens of type B. We chose this configuration because we wanted to have a substantial majority of A type citizens, and also wanted to make sure that the number of Bs as well as the total number of citizens is odd, in order to ensure that no tie-breaking problem in the voting stages would occur. Space limitations did not allow us to use even larger numbers, given that we wanted to have at least two complete countries in parallel in every session for reasons of anonymity.

The three treatments of our experiment involve three different payoff functions for the citizens of region $B$. All are derived from the function $\Pi_{B}=270+1080 x^{\beta}$, where $x \in[0 ; 1]$ is the autonomy level. Note that the linear transformation of the payoff functions, which we applied to generate more convenient integer payoffs in the experimental set-up, does not alter the theoretical predictions in any way. Type A players' payoffs were also transformed as $\Pi_{\mathrm{B}}=1350-1080 \mathrm{x}$, for the same reason. In one treatment, which we label "weakly concave" (WC hereafter) the value for $\beta$ was set to 1.38. A second, so-called "medium concave" (MC) treatment, this value was set $\beta=5.99$. Finally, we conducted a "strongly concave" (SC) treatment with $\beta=18.65$. The parameter values were chosen such that there was one autonomy level in which payoffs for all citizens were equal. Figure 5 visualises the payoff functions we used in the experimental sessions. ${ }^{12}$

\footnotetext{
${ }^{12}$ We do not study the case of convex preferences of the Bs. We conducted a pilot session using a moderately concave payoff function and no payoff-equalising focal point. In this session, 39 out of 40 games ended in conflict. We figured that to give peace a chance, we would need to create a more favourable environment. For the first real session (MC treatment) we increased concavity and introduced payoff-equalising outcomes.
} 


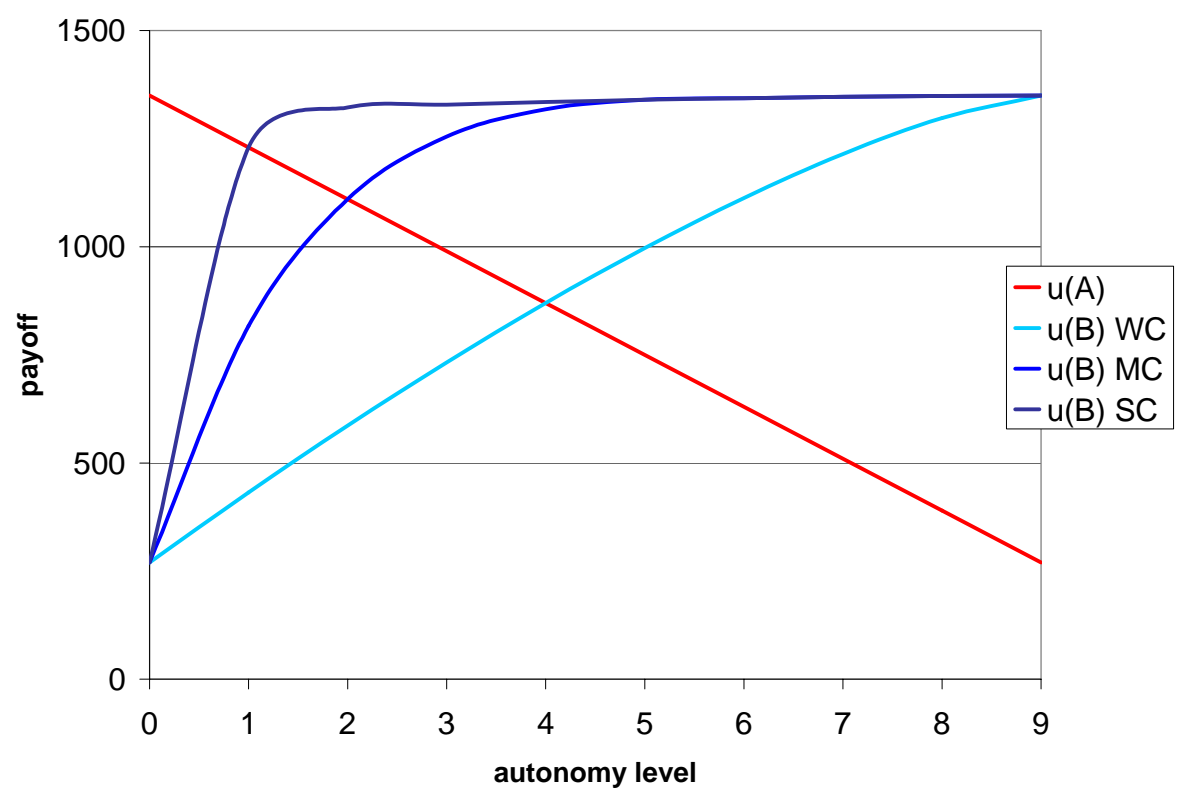

Figure 5. Payoff functions in the experiment

We limited the number of feasible autonomy levels to a discrete grid of 10 equidistant levels, again to improve the presentation of the game to participants. As a result of these manipulations we obtain payoff tables as reproduced in table 1. In the three different treatments the column for the payoff of the As was used together with one of the three columns corresponding to the payoffs of the Bs. These payoffs are rounded values as obtained from the above functions, with the following exception. In the MC and SC treatments, more than one high autonomy level would yield the maximum payoff of 1350 . To prevent possible ambiguity resulting from this we slightly changed the payoffs in these cases. In table 1 the subgame perfect equilibrium predictions are shaded. ${ }^{13}$ Lower autonomy levels than the equilibrium imply a prediction of conflict, since what the Bs obtain is lower than their conflict payoff.

\subsection{The conduct of the experiment}

The experiment was conducted at the Universitat Autònoma de Barcelona (UAB), Spain. The experiment was computerised, with software developed using the RatImage programming package (Abbink and Sadrieh (1995)). ${ }^{14}$ Subjects were recruited with posters placed all over the university campus. Each subject was allowed to participate in only one session, and no subject had participated in experiments similar to the present one. The subjects were undergraduate students from a wide range of disciplines, with slightly more women than men.

\footnotetext{
${ }^{13}$ Apart from the subgame-perfect equilibrium some other distributions of the ones shown in table 1 are worth highlighting. The egalitarian distribution is for WC at an autonomy level of 4, for MC at a level of 2 and for SC at a level of 1 , which coincides with the subgame-perfect equilibrium. The utilitarian distributions are for WC at 0 , for $\mathrm{MC}$ at 2 and for $\mathrm{SC}$ at 1.

${ }^{14}$ The appendix contains a copy of the instructions.
} 
The participants in the experiment were mostly Catalan and Spanish students. We chose this location for the experiment because these subjects are precisely immersed in a conflict albeit a peaceful one - of the type that we want to study. Thus the participants could be seen as more representative of the real-life agents than participants in a country without interregional dispute. The agents in the model represent voters who have pronounced political opinions, but are not necessarily themselves politicians or professionals in policy-oriented areas. So students, who are well-educated potential opinion leaders, seemed the most appropriate subject pool for our study. ${ }^{15}$

Table 1. The payoffs in the three treatments of the experiment

\begin{tabular}{ccccc}
\hline Autonomy level & Each A receives & \multicolumn{3}{c}{ Each B receives } \\
& & WC & MC & SC \\
\hline 0 & 1350 & 270 & 270 & 270 \\
1 & 1230 & 432 & 817 & 1230 \\
2 & 1110 & 587 & 1110 & 1322 \\
3 & 990 & 733 & 1255 & 1329 \\
4 & 870 & 870 & 1318 & 1335 \\
5 & 750 & 997 & 1340 & 1340 \\
6 & 630 & 1113 & 1344 & 1344 \\
7 & 510 & 1214 & 1347 & 1347 \\
8 & 390 & 1298 & 1349 & 1349 \\
9 & 270 & 1350 & 1350 & 1350 \\
\hline
\end{tabular}

In each session two experimental countries were run in parallel. There was no migration between these countries and subjects interacted in fixed groups of 9 subjects. Subjects were not told who of the other participants were in the same group, but they knew that the composition of the groups did not change. The subjects were seated distantly from one another in order to ensure that they could not influence each other's behaviour other than via their decisions in the game.

Each session began with an introductory talk. A research assistant read aloud the written instructions (reproduced in the appendix). The language used in the instructions was natural, i.e. we did not disguise the situation by using abstract terms only. Players were labelled "citizens" living in two "regions" of a "country", and they decided on "levels of autonomy" and "opening a conflict" (translations from Spanish). Compared with a neutral framing this choice of language has two advantages. First, we expected the parallelism between experiment and real-life environment to be improved if the language in the experiment echoes the one used in real life. ${ }^{16}$ Second, the rather complex multi-stage structure of the game was

\footnotetext{
${ }^{15}$ For a discussion of subject pool issues see Harrison and List (2004). In their taxonomy of experiments our study comes closest to a conventional lab experiment, though the use of a Catalan subject pool adds an element of an artefactual field experiment as well.

${ }^{16}$ However, the effect might not be strong. Evidence for the effects of instruction framing has been very mixed so far. In a tax evasion experiment Baldry (1986) finds far more evasion if the task is presented neutrally as a
} 
much more accessible to participants when the situation was presented in a familiar context. A potential downside of natural language is that it could be more prone to suggestive phrasing. We addressed this problem by avoiding expressions that were too heavily loaded in the Spanish-Catalan policy debate.

After all questions were answered, the computer programme started play. In each round every citizen A proposed an autonomy level first; one of them was then randomly selected. This way we could generate a richer data set for citizen A proposals. All citizens were then informed about the selected proposal and asked to vote on it. Like in most real-world ballots, players were informed about the distribution of votes, separately for the two regions, but not on individual voting behaviour. Then the type B citizens voted on whether or not to open the conflict for full autonomy. Again, the distribution of votes was transmitted to all citizens. If a conflict was opened, then all players were asked for their contributions, after which the total contributions in each region was made public. The lottery was then played out, visualised by a wheel of fortune on the computer screens. Participants interacted in fixed groups for 20 rounds.

The total earnings of a subject from participating in this experiment were equal to the sum of all the profits he made during the experiment. A session lasted for about two hours (this includes the time spent to read the instructions). At the end of the experiment, subjects were paid their total earnings anonymously in cash, at a conversion rate of one euro for 1500 talers. Subjects earned between $€ 5.00$ and $€ 55.40$ with an average of $€ 27.58$, which is considerably more than students' regular wage in Barcelona. At the time of the experiment, the exchange rate to other major currencies was approximately US- $\$ 1.20$ and $£ 0.70$ for one euro.

We conducted four sessions with each treatment. In each session two countries were played in parallel. Since there is no interaction between citizens in different countries, each country can be considered an independent observation. Thus we gathered eight observations per treatment.

\section{Results}

The main focus of our experiment is on the likelihood of conflict and its resolution under the different sets of induced preferences. Therefore, we jump in our results presentation to the last stage of the game and first look at the frequency of an outbreak of conflict. Figure 6 shows the relative frequency of conflict in the three treatments over the twenty rounds of the experiment, aggregated over all sessions in each treatment. ${ }^{17}$ Recall that concavity of

\footnotetext{
gambling opportunity. Alm, McClelland, and Schulze (1992), however, do not find any differences. A study by Burnham, McCabe, and Smith (2000) reports significant less trustful choices in a reciprocity game when the other player is called "opponent" rather than "partner". On the other hand, Abbink and Hennig-Schmidt (2002) do not find significantly different behaviour between a neutrally and a naturally worded version of a bribery experiment.

${ }^{17}$ In figure 6 we include both conflicts that emerge after an equilibrium or an even more favourable proposal and those that emerge after an out of equilibrium proposal.
} 
preferences in all treatments implies that there should be no conflict at all according to the subgame-perfect equilibrium prediction.

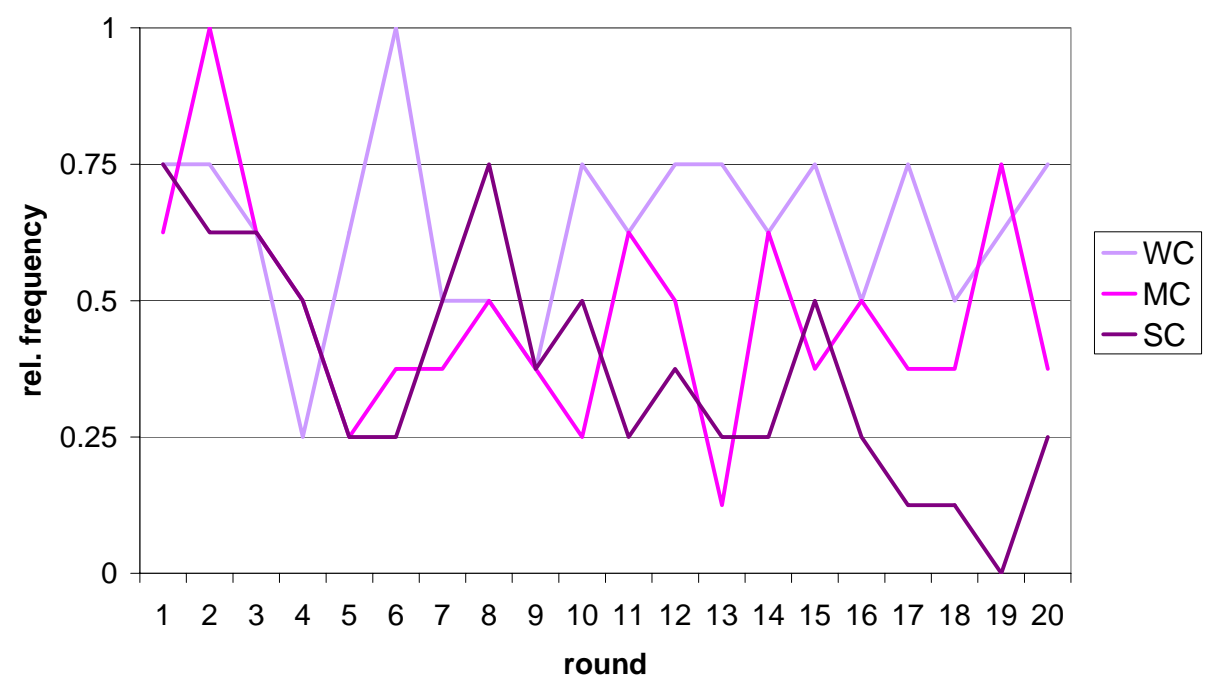

Figure 6. Conflict frequency

In all three treatments the proportion of rounds in which no peaceful solution could be achieved is substantial. Even in the strongly concave condition more than one third $(37.5 \%)$ of all rounds ended in conflict. This is surprising given that the autonomy level of 1 in this treatment is vastly more efficient than conflict. Recall that at this level each citizen gains a sure payoff of 1230, which is only slightly less than the winning party's per-capita payoff of 1350 (while the losers get a mere 270 each). In addition, citizens lose their contributions to the war chest in conflict. While in the SC treatment the frequency of conflict diminishes over the course of the experiment, no such trend can be observed in the MC and the WC treatment. Rather, conflict frequencies stay high at slightly less than one half even in later rounds. Recall that in these treatments there exist peaceful solutions, autonomy levels 2 and 1 respectively, that provide high (1110 and 1230 talers, respectively) and equal payoffs to all citizens.

Over-fighting is strongly pronounced in all three treatments of the experiment, but we can establish a relationship between concavity and the likelihood of conflict. The respective conflict frequencies are $63.8 \%, 47.5 \%$ and $37.5 \%$ in the $\mathrm{WC}, \mathrm{MC}$, and $\mathrm{SC}$ treatment. Thus there is a tendency that a higher degree of concavity leads to a lower incidence of conflict. However, this effect is statistically significant only for the comparison between the WC and the SC treatment ( $\alpha=0.01$ one-sided, Fisher's two-sample randomisation test). The other two pair-wise comparisons (WC vs. MC and MC vs. SC) are not significant.

Result 1. In all three treatments the B citizens often vote for conflict even if they had previously accepted the proposal for a new status. Instead of the absence of conflict predicted 
in the subgame equilibrium we observe conflict frequencies of $63.8 \%$ for SC, $47.5 \%$ for $M C$ and $37.5 \%$ for $W C$.

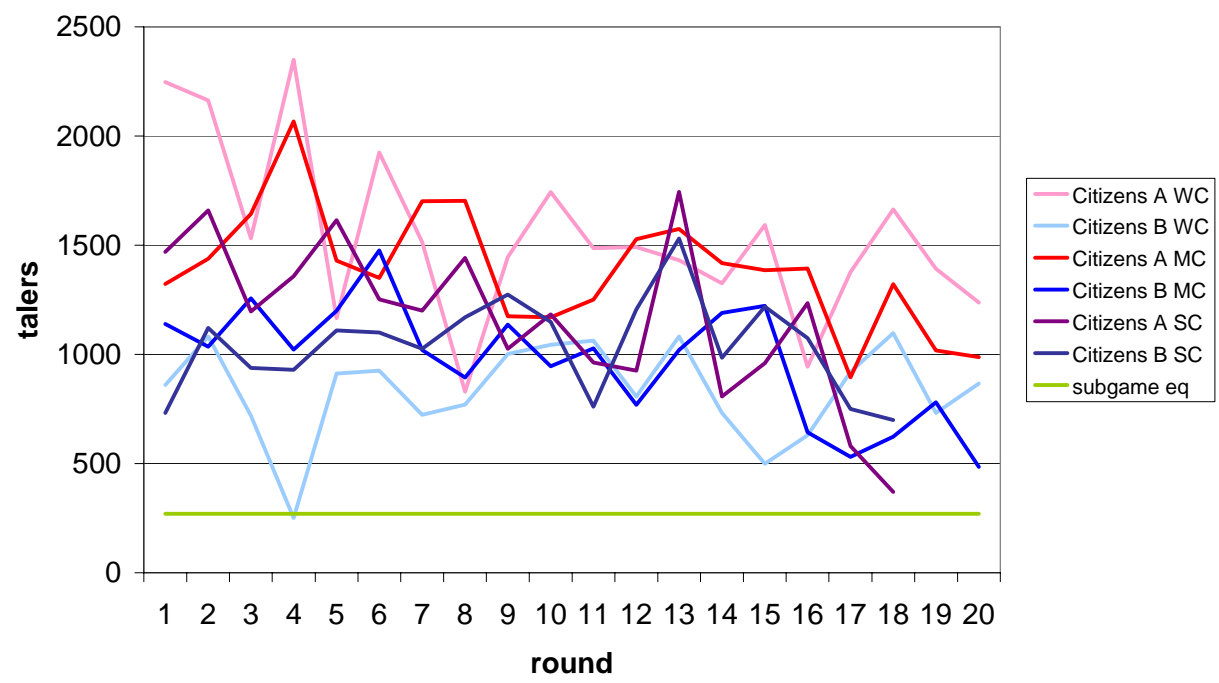

Figure 7. Average aggregate contribution to conflict

The core of our interest is in the existence of peaceful solutions to inter-regional conflicts of the ethno-political type. In that respect result 1 can be seen as the bottom line. However, once a conflict has erupted there is still a question of how strong or intense the conflict will be in terms of the contributions to the war chests. Figure 7 shows the average total group contributions, conditional on there being a conflict, over the twenty rounds of the experiment. ${ }^{18}$ The subgame equilibrium prediction for the conflict games considered in isolation is a total contribution of 270 for both the group of A citizens and the one of the B citizens, with individual contributions of 45 for each $\mathrm{A}$ and 90 for each $\mathrm{B}$ citizen.

One can see that the tendency towards over-fighting manifests itself further in the massive contribution levels once a conflict has been opened. In fact the average contribution we observe in the experiment is 4.4 times higher than in the subgame equilibrium, with an average total contribution of 1376.3 for the A and 949.4 for the B citizens. Thus, not only is there far more conflict than predicted, but if there is conflict it is also far more intense. ${ }^{19}$

Significant treatment differences cannot be observed with respect to the contributions. However, once a conflict breaks out the subgame is identical in the three treatments, thus the absence of such effects might not be surprising.

\footnotetext{
${ }^{18}$ For the SC treatment there was never conflict in round 19, in round 20 there were conflicts and the average contributions were 1756 for the A citizens and 1009.5 for the B citizens.

19 Most experimental studies on rent-seeking games show that investment in conflict is larger than in equilibrium, but to a far lesser extent. In all existing rent-seeking experiments individuals play for their own good. In our experiment individuals contribute to their group effort. The theoretical prediction would let us expect strong free-riding behaviour. Such an effect, however, is virtually absent in the data.
} 
Result 2. In all three treatments we observe strong over-fighting with respect to the equilibrium level of the conflict stage as such.

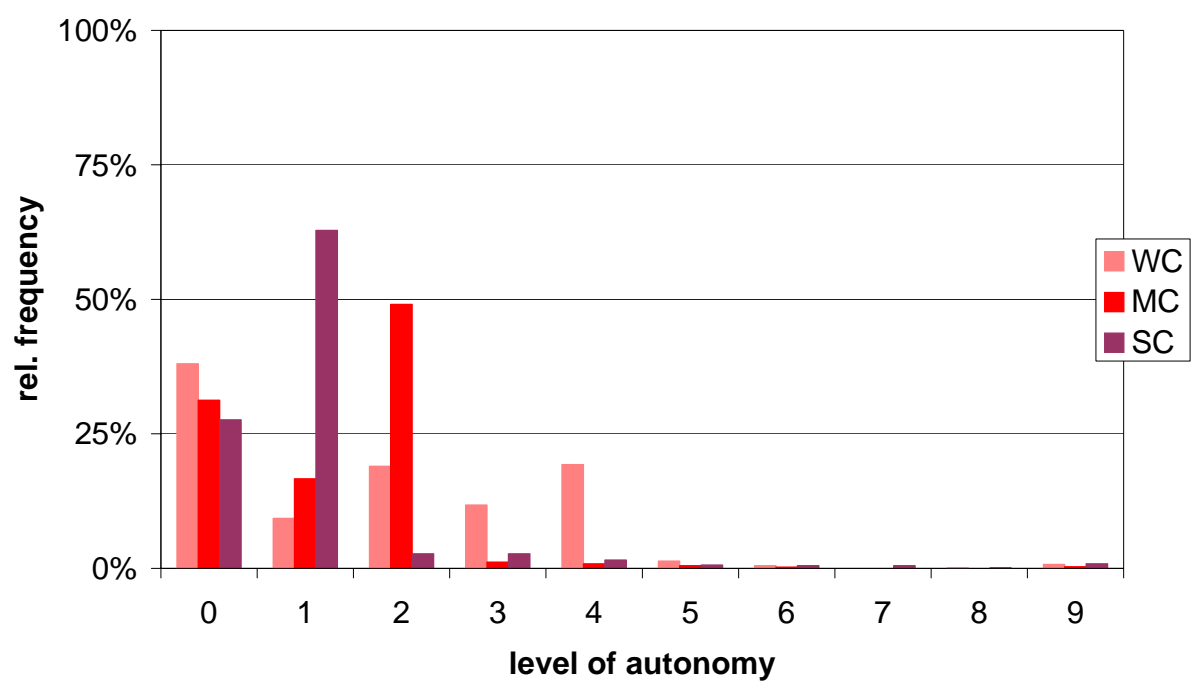

Figure 8. Distribution of citizens A's proposals

Now that we have seen how frequently conflicts erupt and how strong they are we move to looking at how conflict comes about. We start with the distribution of the proposals made by the As in the first stage, which are shown in figure 8 . This includes all proposals made by the A citizens and not only those randomly selected to actually be presented to the B citizens.

A useful first approximation to the data is to distinguish between equilibrium and better-thanequilibrium (for the $\mathrm{B}$ citizens) proposals and the rest. For the $\mathrm{WC}$ treatment such offers are made in about $1 / 3$ of the proposals, while for the $\mathrm{MC}$ and the $\mathrm{SC}$ treatments they are around 2/3. Overall, type A citizens frequently fail to make proposals acceptable to the B citizens. About one third of the proposals involve an autonomy level of zero, which means the citizen A refuses to offer any level of autonomy and therefore near-certainly opts for conflict.

In the WC treatment the payoff-equalising level is chosen somewhat more frequently than the equilibrium level. In the MC and SC treatments the modal offer is the level in which both types' payoffs are equal, though there is still a high frequency of other proposals. We summarise this in the following statement:

Result 3. The A citizens frequently propose to the $B$ citizens autonomy levels that in equilibrium are unacceptable.

We now move to voting behaviour in stage two, the referendum stage. Tables 2 to 4 show the citizens' voting behaviour given the proposed autonomy levels, where the row corresponding to the subgame equilibrium is shown in bold. The data shows the voting reaction to the 
proposals that were effectively chosen for being voted over. ${ }^{20}$ Focus first on the voting response to the equilibrium proposal. For the WC condition the favourable votes of the A and the B citizens are $66.7 \%$ and $75.9 \%$. In expected terms this implies 6 favourable votes which is more than enough for this proposal to be approved in referendum. Indeed, this is true for all three relevant levels 0 to 4 . For MC (SC) treatment the voting response to the equilibrium is $85.5 \%(91.8 \%)$ and $62.4 \%(91.2 \%)$ for the A and the B citizens respectively; in both cases this is enough for the equilibrium to be adopted.

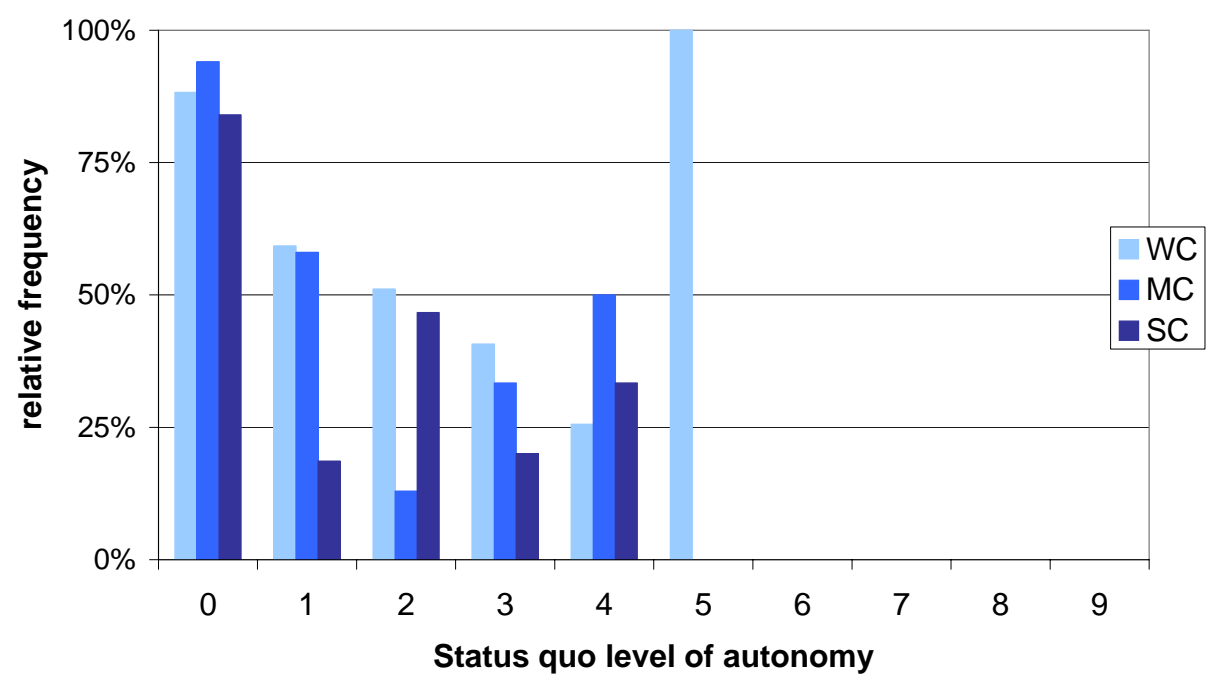

Figure 9. Votes in favour of conflict

Proposals that win the referendum with less than $2 / 3$ of the votes of the $\mathrm{B}$ citizens, like proposal 0,1 and 2 in the WC treatment, seem headed for conflict, as prescribed in equilibrium. However, those proposals that receive $2 / 3$ of the $B$ votes may not necessarily lead to peace, since B citizens who want to vote for conflict may still vote in favour of a proposal. Doing so they ensure a higher payoff than in the original status quo should the fellow B citizens opt against conflict. As will be shown below, B citizens indeed tend to vote in favour of autonomy levels, for which they later open conflict.

Result 4. The equilibrium receives an overall (expected) majority in all three treatments and in $W C$ and SC they receive a majority in both regions

Figure 9 shows behaviour in the third stage of the game, B citizens' voting behaviour with respect to conflict. ${ }^{21}$ Start with the WC treatment and observe that the equilibrium proposal is rejected at this stage in around $40 \%$ of the case, in spite of the fact that at the referendum stage it received 75.9 favourable votes of the B citizens. Moreover, the for the Bs more

\footnotetext{
${ }^{20}$ Observe that if an autonomy level of zero is proposed, then a large majority of citizens A vote in favour, and most citizens B vote against. This can be interpreted as the wish to make a statement, given that in this case the ballot is irrelevant, as it involves a choice between two identical options.

${ }^{21}$ The $100 \%$ bar for autonomy level 5 in the WC treatment is likely to be an outlier, since this level was proposed only twice in this treatment.
} 
favourable proposal 4 is also rejected in $25 \%$ of the cases, in contrast to the $93.3 \%$ favorable $\mathrm{B}$ votes that the proposal received at the referendum stage

Table 2. Citizens' voting behaviour (weakly concave treatment)

\begin{tabular}{rrrrrrrr}
\hline $\begin{array}{r}\text { proposed } \\
\begin{array}{r}\text { Autonomy } \\
\text { level }\end{array}\end{array}$ & Freq. & $\begin{array}{r}\text { Citizens A } \\
\text { yes votes }\end{array}$ & $\begin{array}{r}\text { Citizens A } \\
\text { no votes }\end{array}$ & $\begin{array}{r}\text { Citizens B } \\
\text { yes votes }\end{array}$ & $\begin{array}{r}\text { Citizens B } \\
\text { no votes }\end{array}$ & $\begin{array}{r}\text { Citizens A } \\
\% \text { yes }\end{array}$ & $\begin{array}{r}\text { Citizens B } \\
\% \text { yes }\end{array}$ \\
\hline 0 & 71 & 361 & 65 & 18 & 195 & $84.7 \%$ & $8.5 \%$ \\
1 & 9 & 46 & 8 & 10 & 17 & $85.2 \%$ & $37.0 \%$ \\
2 & 30 & 141 & 39 & 56 & 34 & $78.3 \%$ & $62.2 \%$ \\
3 & 18 & 72 & 36 & 41 & 13 & $66.7 \%$ & $75.9 \%$ \\
4 & 30 & 88 & 92 & 84 & 6 & $48.9 \%$ & $93.3 \%$ \\
5 & 2 & 3 & 9 & 5 & 1 & $25.0 \%$ & $83.3 \%$ \\
6 & 0 & 0 & 0 & 0 & 0 & - & - \\
7 & 0 & 0 & 0 & 0 & 0 & - & - \\
8 & 0 & 0 & 0 & 0 & 0 & - & - \\
9 & 0 & 0 & 0 & 0 & 0 & - & - \\
\hline
\end{tabular}

Table 3. Citizens' voting behaviour (medium concave treatment)

\begin{tabular}{rrrrrrrr}
\hline $\begin{array}{r}\text { proposed } \\
\begin{array}{r}\text { Autonomy } \\
\text { level }\end{array}\end{array}$ & Freq. & $\begin{array}{r}\text { Citizens A } \\
\text { yes votes }\end{array}$ & $\begin{array}{r}\text { Citizens A } \\
\text { no votes }\end{array}$ & $\begin{array}{r}\text { Citizens B } \\
\text { yes votes }\end{array}$ & $\begin{array}{r}\text { Citizens B } \\
\text { no votes }\end{array}$ & $\begin{array}{r}\text { Citizens A } \\
\% \text { yes }\end{array}$ & $\begin{array}{r}\text { Citizens B } \\
\% \text { yes }\end{array}$ \\
\hline 0 & 56 & 289 & 47 & 12 & 156 & $86.0 \%$ & $7.1 \%$ \\
1 & 31 & 159 & 27 & 58 & 35 & $85.5 \%$ & $62.4 \%$ \\
2 & 67 & 347 & 55 & 188 & 13 & $86.3 \%$ & $93.5 \%$ \\
3 & 3 & 6 & 12 & 9 & 0 & $33.3 \%$ & $100.0 \%$ \\
4 & 2 & 4 & 8 & 5 & 1 & $33.3 \%$ & $83.3 \%$ \\
5 & 1 & 2 & 4 & 3 & 0 & $33.3 \%$ & $100.0 \%$ \\
6 & 0 & 0 & 0 & 0 & 0 & - & - \\
7 & 0 & 0 & 0 & 0 & 0 & - & - \\
8 & 0 & 0 & 0 & 0 & 0 & - & - \\
9 & 0 & 0 & 0 & 0 & 0 & - & - \\
\hline
\end{tabular}

Table 4. Citizens' voting behaviour (strongly concave treatment)

\begin{tabular}{rrrrrrrr}
\hline $\begin{array}{r}\text { proposed } \\
\begin{array}{r}\text { utonomy } \\
\text { level }\end{array}\end{array}$ & Freq. & $\begin{array}{r}\text { Citizens A } \\
\text { yes votes }\end{array}$ & $\begin{array}{r}\text { Citizens A } \\
\text { no votes }\end{array}$ & $\begin{array}{r}\text { Citizens B } \\
\text { yes votes }\end{array}$ & $\begin{array}{r}\text { Citizens B } \\
\text { no votes }\end{array}$ & $\begin{array}{r}\text { Citizens A } \\
\% \text { yes }\end{array}$ & $\begin{array}{r}\text { Citizens B } \\
\% \text { yes }\end{array}$ \\
\hline 0 & 50 & 236 & 64 & 18 & 132 & $78.7 \%$ & $12.0 \%$ \\
1 & 95 & 523 & 47 & 260 & 25 & $91.8 \%$ & $91.2 \%$ \\
2 & 5 & 12 & 18 & 12 & 3 & $40.0 \%$ & $80.0 \%$ \\
3 & 5 & 27 & 3 & 11 & 4 & $90.0 \%$ & $73.3 \%$ \\
4 & 2 & 5 & 7 & 5 & 1 & $41.7 \%$ & $83.3 \%$ \\
5 & 0 & 0 & 0 & 0 & 0 & - & - \\
6 & 2 & 10 & 2 & 6 & 0 & $83.3 \%$ & $100.0 \%$ \\
7 & 1 & 4 & 2 & 3 & 0 & $66.7 \%$ & $100.0 \%$ \\
8 & 0 & 0 & 0 & 0 & 0 & - & - \\
9 & 0 & 0 & 0 & 0 & 0 & - & - \\
\hline
\end{tabular}

For the MC treatment the equilibrium proposal - accepted with $62.4 \%$ at the referendum stage - is now rejected in over $50 \%$ of the cases. Even the more favourable proposal 2 is rejected in more than $10 \%$ of instances; the data for proposal levels 3 and 4 can be neglected since they are very unrepresentative. For the SC treatment, finally, things look much better, but the 
rejection rate is still around $20 \%$; for this case only the data for proposals of levels 0 and 1 are reasonable to look at.

\section{Summary and Conclusions}

We study an experimental game capturing essential features of a dependent region's fight for more political autonomy in a democratic context. For the concave preferences we study theory predicts a "peace equilibrium" with an intermediate degree of political autonomy, and no conflict.

In contrast to this prediction we observe, at different points of the game, three kinds of deviations, which lead to very costly conflicts. First, the citizens of the dominant region often fail to make proposals that would be acceptable to the citizens of the dominated region, even though such proposals appear to be, from the material viewpoint, satisfactory for the citizens of the dominant region. Second, the citizens of the dominated region frequently reject equilibrium proposal and even more favourable ones and open a conflict. Finally, once a conflict emerges the resources spent on it are substantially more than what should be spent in equilibrium.

Emotional forces like the ones mentioned in the introduction appear to be a powerful force in our experiment. We use the term powerful here, since the behaviour we observe leads to very considerable material losses in relation to the "peace equilibrium". The interaction between the two groups leads to the emergence of some kind of group cohesion, which in turn leads to unacceptable offers and the rejection of reasonable offers. This seems to trigger anger and results in a priori unreasonable investments in the inter-group conflict. Our results are an instance of how political, psychological and economic factors can interact: a biased - albeit democratic - political process can trigger emotional forces which lead to an important destruction of material resources.

The behaviour we observe is not simply guided by a tendency to gain material benefit for one's group and to hurt members of the other group as documented in Tajfel, Billig, Bundy and Flament (1971). Our results are more related to those obtained by Bornstein and BenYossef (1994) using a social dilemma game. They find that placing people into groups triggers higher competitiveness, even though that competition may result in losses for all concerned. Pemberton, Insko and Schopler (1996) suggest that part of the problems could be that individuals, assuming that acting in groups triggers competitive behaviour, expect the members of the other group to act in a competitive way. This may lead to the consistency of expectations and behaviour of both groups. In our particular framework this would explain why the As act aggressively towards the Bs by often not proposing equilibrium outcomes; they may simply act in anticipation of aggressive responses by the Bs. The preponderant position of the As in our environment may be seen as lacking legitimacy. Tyler (2006) 
surveys some psychological research that documents - for example Brown and Ross (1978) that if differences between groups are perceived as illegitimate, they may generate anger.

In relation to the interpretation of actual ethno-political conflicts outside the laboratory the results are not encouraging. We observe very unreasonable behaviour in the very moderately emotional climate of the lab. The emotional forces that lead to the behaviour we observe can be conjectured to be much more intense in natural environments involving communities that have been in conflict for generations.

Here the question arises as to how, in the light of our results, costly conflict could be reduced. One natural candidate is mediation by a neutral third party. Part of the problem with our environment is that the A citizens have the initiative in proposing an outcome. This seems to make them somehow aggressive in their demands. At the same time the B citizens respond aggressively to the As proposals, as if they felt hurt in their pride due to the fact that they are assigned a more passive role. If a proposal for a reasonable arrangement were made by an independent mediator much of the aggressiveness displayed by both sides might disappear. Indeed, mediation is very frequently observed in situation of conflicts between communities, as in the former Yugoslavia.

Another way to improve relations between the two communities could be a change in the rules of the game to a situation with more symmetric roles for the As and the Bs. Perhaps if the initial proposals were launched by a small subset of As and Bs, a balanced expert commission of some sort, acceptance of equilibrium proposals might increase.

We close with some speculative remarks intended to inspire further research. Our results show that concavity of relative preferences between the two groups does matter, albeit only moderately. In the experiment, of course, these preferences were induced by payoff tables. External validation of our results would require extensive survey studies to assess the preference profile in different countries in which autonomy struggles prevail. Such studies would systematically assess how different bundles of policy measures can be ordered to preference profiles as we use in our model. It would then be possible to evaluate the concavity of relative preferences between the median voters in the regions. In a cross-cultural survey our results could be empirically validated and potentially guide policy-makers in their effort to find peaceful solutions to the respective countries' problems. 


\section{References}

Abadie A and J Gardeazabal (2003), "The Economic Costs of Conflict: A Case Study of the Basque Country," American Economic Review, 93, 113-132.

Abbink K and H Hennig-Schmidt (2002): "Neutral versus Loaded Framing in a Bribery Experiment". Bonn Econ. Discussion Paper 23/2002, University of Bonn.

Abbink K and S Pezzini (2005), "Determinants of Revolt: Evidence from Survey and Laboratory Data," CeDEx Discussion Paper 2005-01, University of Nottingham.

Abbink K and A Sadrieh (1995): "RatImage - Research Assistance Toolbox for Computer-Aided Human Behaviour Experiments". SFB Discussion Paper B-325, University of Bonn.

Alesina A and E Spolaore (1997), "On the Number and Size of Nations," Quarterly Journal of Economics, 112 , 1027-1056.

Alm J, G McClelland and W Schulze (1992): “Why do people pay taxes?” Journal of Public Economics, 48, 21-38.

Anderson L and S Stafford (2003), "An Experimental Analysis of Rent-Seeking under Varying Competitive Conditions," Public Choice, 115, 199-216.

Baldry J (1986): "Tax Evasion Is Not a Gamble - A Report on Two Experiments". Economic Letters, 22, 333-335.

Bornstein G and M Ben-Yossef (1994), "Cooperation in inter-group and single-group social dilemmas," Journal of Experimental Social Psychology,” 30, 52-67.

Brown R and GF Ross (1982), "The battle for acceptance: an exploration into the dynamics of intergroup behaviour." In H Tajfel (ed.) Social identity and intergroup relations, Cambridge University Press.

Burnham T, K McCabe and V Smith (2000): "Friend- or Foe: Intentionality Priming in an Extensive Form Trust Game". Journal of Economic Behavior and Organization, 43, 57-74.

David D and R Reilly (1998), "Do Too Many Cooks Spoil the Stew? An Experimental Analysis of Rent-seeking and the Role of a Strategic Buyer," Public Choice, 95, 89-115

Duffy J and M Kim (2004), "Anarchy in the Laboratory (and the Role of the State)," Journal of Economic Behavior and Organization, forthcoming.

Durham Y, J Hirshleifer and V Smith (1998), "Do the Rich get Richer and the Poor Poorer? Experimental tests of a Model of Power," American Economic Review, 88, 970-983.

Esteban J and D Ray (2005), “A Model of Ethnic Conflict,” mimeo, Institut d'Anàlisi Econòmica (CSIC).

Hale HE (2000), "The Parade of Sovereignties: Testing Theories of Secession in the Soviet Setting," British Journal of Political Science, 30, 31-56.

Hale HE (2004), "Divided We Stand: Institutional Sources of Ethno-federal Survival and Collapse," World Collapse, 56, 165-193.

Harrison G, and J List (2004): “Field experiments.” Journal of Economic Literature, 42, 1009-1055.

Hechter M (2000), Containing Nationalism, Oxford University Press, Oxford.

Hirshleifer J (2001), “Appeasement: Can It Work?,” American Economic Review, 91, 342- 346.

Jehiel P and J-F Thisse (2005), "How to Win a Decision in a Confederation," Journal of Public Economics, 89, 1191-1210.

Kyriacou AP (2005), "Rationality, Ethnicity and Institutions: A Survey of Issues and Results," Journal of Economic Surveys, 19, 23-42.

Le Breton M and S Weber (2003), "The Art of Making Everybody Happy: How to Prevent a Secession," IMF Staff Papers, 50, 403-435.

Lustick IS, D Miodownik and RE Eidelson (2004), “Secessionism in Multicultural States: Does Sharing Power Prevent or Encourage it?," American Political Science Review, 98, 209-229.

Millner EL and MD Prat (1989), "An Experimental Investigation of Efficient Rent-seeking," Public Choice, 62, 139-151.

Pemberton MB, CA Insko and J Schopler (1996), "Memory for and experience of differential competitive behaviour of individuals and groups," Journal of Personality and Social Psychology, 71, 953-966.

Potters J, CG de Vries and F van Winden (1998), "An Experimental Examination of Rational Rent-seeking," European Journal of Political Economy, 14, 783-800.

Ruta M (2005), "Economic Theories of Political (Dis)Integration," Journal of Economic Surveys, 19, 1-21.

Schelling T (1960), The Strategy of Conflict, Harvard University Press, Cambridge MA.

Tajfel H, MG Billig, RP Bundy and C Flament (1971), "Social categorization and intergroup behaviour," Journal of Social Psychology, 1, 149-178.

Tyler TR (2006), Psychological Perspectives on Legitimacy and Legitimation. Annual Review of Psychology 57: $375-400$.

Weimann J, CL Yang und C Vogt (2000): “An experiment on sequential rent-seeking”, Journal of Economic Behavior and Organization, 41, 405-426.

Wood, EJ (2003), "Modeling Robust Settlements to Civil War: Indivisible Stakes and Distributional Compromises," Santa Fe Institute, Working Paper \# 3-10-056. 


\section{Appendix. Instructions}

\section{General information}

We thank you for coming to the experiment. The purpose of this session is to study how people make decisions in a particular situation. During the session it is not permitted to talk or communicate with the other participants. If you have a question, please raise your hand and one of us will come to your desk to answer it. During the session you will earn money. At the end of the session the amount you will have earned during the experiment will be paid to you in cash. Payments are confidential, we will not inform any of the other participants of the amount you have earned.

During the experiment you will be in a group with eight other participants. You will be grouped with the same participants throughout the experiment. You will not be informed of the identity of the persons you are grouped with. Six of the persons in your group will be in subgroup A and three in subgroup B throughout the experiment.

The experiment consists of 20 separate rounds.

\section{Decision stages of each round}

In each round participants will make decisions in three stages.

\section{Stage 1}

All participants live together in a country, with the As living in region A and the Bs in region B. Stage 1 of every round starts with original status quo payoffs of $\mathrm{x}$ for each of the participants in region $\mathrm{A}$ and of $\mathrm{y}$ for each of the participants in region $\mathrm{B}$. These original status quo payoffs will be the same in all rounds. It is possible that there will be a referendum among all the members of a group about whether to replace the original status quo by another level of autonomy implying a different payoff combination. The table below shows the different possible autonomy level with corresponding payoff combinations.

\begin{tabular}{|c|c|c|c|c|c|c|c|c|c|c|}
\cline { 2 - 10 } \multicolumn{1}{c|}{} & \multicolumn{7}{c|}{ Payoff combinations of the different autonomy levels [see main text] } \\
\hline $\begin{array}{c}\text { Autonomy } \\
\text { level }\end{array}$ & $\begin{array}{c}\text { Original } \\
\text { status quo }\end{array}$ & 1 & 2 & 3 & 4 & 5 & 6 & 7 & 8 & $\begin{array}{c}\text { Full } \\
\text { autonomy }\end{array}$ \\
\hline Every A gets & & & & & & & & & & \\
\hline Every B gets & & & & & & & & & & \\
\hline
\end{tabular}

Before the referendum can take place each of the As will propose simultaneously which autonomy level (original status quo, I, II,..., full autonomy) they want to replace the original status quo with. The proposal of one of the As will be chosen at random. If the randomly chosen proposal is the original status quo itself, then the original status quo remains, no 
referendum takes place and the round moves directly to stage 2 . If the randomly chosen proposal is not the status quo then all the As and Bs will be called to vote in favour of the new proposal or the original status quo. Whichever of the two possibilities obtains more votes wins and becomes the new status quo. Then the round moves to stage 2 .

\section{Stage 2}

In this stage there will be a referendum among only the Bs to decide whether they accept what now is the status quo. If the majority of the Bs says yes the round ends and the As and Bs in the group earn the payoff corresponding to the new status quo. If the majority says no, then a conflict arises and the round moves to stage 3.

\section{Stage 3}

In this stage each of the participants in a group can campaign by investing money either in a "original status quo account" or in a "full autonomy" account. All participants make this decision simultaneously. Once all have made their decision the computer will randomly determine whether the payoff combination of the original status quo or the payoff combination of full autonomy will be implemented. The probability that the original status quo will be selected is:

(Money in the original status quo account)/(Money in the original status quo account + Money in the full autonomy account),

and the probability that full autonomy is selected is:

(Money in the original full autonomy account)/(Money in the original status quo account + Money in the full autonomy account).

Note that the two probabilities sum to one, i.e. one of the two payoffs, the original status quo or full autonomy, will be selected with certainty. Note also that the more money in one of the accounts relative to the other, the more likely that the first account will be selected.

Once the final payoff combination has been selected the round ends. After that the next round will start, until a total of 20 rounds.

\section{Earnings}

At the beginning of the experiment each of you will receive 1000 talers credited to your account. After each round, your round earnings are credited to your account. At any moment during the experiment you will be able to check the money in your account on the screen.

At the end of the experiment the talers will be converted to euros at the exchange rate of 1.50 euros for each 1000 talers. 